\title{
Long non-coding RNA ANRIL predicts poor prognosis and promotes invasion/metastasis in serous ovarian cancer
}

\author{
JUN-JUN QIU ${ }^{1-3}$, YING-YING LIN ${ }^{4}$, JING-XIN DING ${ }^{1-3}$, \\ WEI-WEI FENG ${ }^{1-3}$, HONG-YAN JIN ${ }^{1-3}$ and KE-QIN HUA ${ }^{1-3}$ \\ ${ }^{1}$ Department of Gynecology, Obstetrics and Gynecology Hospital, Fudan University, Shanghai 200011; \\ ${ }^{2}$ Department of Obstetrics and Gynecology of Shanghai Medical College, Fudan University, \\ Shanghai 200032; ${ }^{3}$ Shanghai Key Laboratory of Female Reproductive Endocrine-Related Diseases, \\ Shanghai 200011; ${ }^{4}$ Department of Neurosurgery, Renji Hospital, School of Medicine, \\ Shanghai Jiao-Tong University, Shanghai 200127, P.R. China
}

Received December 8, 2014; Accepted January 30, 2015

DOI: 10.3892/ijo.2015.2943

\begin{abstract}
Recent studies have highlighted the role of long non-coding RNAs (lncRNAs) in carcinogenesis and have suggested that genes of this class might be used as biomarkers in cancer. However, whether lncRNAs are involved in serous ovarian cancer (SOC) remains largely unknown. In the present study, we focused on IncRNA antisense non-coding RNA in the INK4 locus (ANRIL) and investigated its expression pattern, clinical significance, and biological function in SOC. We found that ANRIL levels were elevated in SOC tissues compared with normal controls and were highly correlated with advanced FIGO stage, high histological grade, lymph node metastasis, and poor prognosis. Multivariate analysis further revealed that ANRIL is an independent prognostic factor for predicting overall survival of SOC patients. In vitro, we compared differential ANRIL levels between SOC parental cell lines (SK-OV-3, HO8910) and highly metastatic sublines (SK-OV-3.ip1, HO8910-PM). Notably, ANRIL was highly expressed in both SK-OV-3.ip1 cells and HO8910-PM cells. SiRNA-mediated ANRIL silencing in these cells impaired cell migration and invasion. Based on the metastasis-related mRNA microarray analysis and subsequent western blotting confirmation, we found that MET and MMP3 are key downstream genes of ANRIL involved in SOC cell migration/ invasion. Together, our data suggest that lncRNA ANRIL plays an important role in SOC invasion/metastasis and could represent a novel biomarker for predicting poor survival as well a promising therapeutic target.
\end{abstract}

Correspondence to: Dr Ke-Qin Hua, Department of Gynecology, Obstetrics and Gynecology Hospital, Fudan University, 419 Fangxie Road, Shanghai 200011, P.R. China

E-mail: huakeqin@126.com

Key words: long non-coding RNA, ANRIL, serous ovarian cancer, metastasis, prognosis

\section{Introduction}

Epithelial ovarian cancer (EOC) consists of multiple histotypes differing in etiology and clinical course. The most prevalent histotype is serous ovarian cancer (SOC), which is highly lethal $(1,2)$. Because of the absence of characteristic symptoms and the lack of effective biomarkers, the majority of SOC patients have widely dispersed intra-peritoneal and/or lymph node metastatic disease at the time of diagnosis $(3,4)$. Despite advances in surgery and chemotherapy over the last few decades, the 5-year survival rate for SOC patients with advanced disease remains $<30 \%(2,5)$. Such an unfavourable prognosis has been largely correlated with tumour metastasis. Therefore, strategies for elucidating the mechanism underlying metastasis and identifying novel biomarkers for SOC are urgently needed.

Long non-coding RNAs (lncRNAs, >200 nt in length), previously disregarded as transcriptional noise, are emerging as new regulators in the cancer paradigm $(6,7)$. An increasing number of discoveries of misregulated lncRNA expression across numerous cancer types have suggested that aberrant lncRNA expression may be a major contributor to tumourigenesis. Further, lncRNAs may add another layer to cancer research because their potential usefulness as biomarkers (8-15). Therefore, to fully understand the complex mechanisms underlying carcinogenesis and cancer metastasis, the role of lncRNAs must be considered.

The antisense non-coding RNA in the INK4 locus (ANRIL) is a recently discovered IncRNA encoded in the chromosome 9p21 region, which has been highlighted as a hotspot for cancer research because this gene locus is often homozygously deleted or transcriptionally silenced in $\sim 40 \%$ of human cancers (16). The data gathered to date strongly implicate ANRIL in the epigenetic regulation of INK4b/ARF/ INK4a tumour suppressors (17-19). In addition, ANRIL has been reported to contribute to a number of cellular events in many cancers facilitating cell proliferation and senescence, suggesting it has a pro-cancerogenic role $(20,21)$. To date, upregulation of ANRIL has gradually become known as a 
primary feature of many human solid carcinomas, including melanoma (19), breast cancer (22), pancreatic carcinoma (23), nasopharyngeal carcinoma (24), basal cell carcinoma (25), glioma (26) and leukemia (27). However, its involvement in SOC remains poorly investigated.

In the present study, we detected the expression of ANRIL in SOC tissues and assessed its association with clinicopathological factors as well as patient prognosis. Additionally, using in vitro assays, we determined its role in metastasis and invasion during SOC progression. We also employed metastasis-related gene mRNA microarrays to investigate the downstream molecular events involving ANRIL and SOC metastasis. Our study highlights the significance of ANRIL in SOC metastasis and prognosis.

\section{Materials and methods}

Patients and tissue samples. A total of 68 SOC tissue samples were obtained from patients admitted to the Department of Gynaecology, Obstetrics and Gynaecology Hospital of Fudan University between August 2005 and December 2008. All diagnoses were confirmed by histology. Patients with borderline ovarian tumours, patients with two or more different malignancies and patients who had received preoperative radiotherapy, chemotherapy, or hormonal therapy were excluded. The control group consisted of 30 normal ovarian epithelial tissue samples obtained from participants diagnosed with uterine fibroids scheduled to undergo hysterectomy and oophorectomy. Patients with ovarian cysts, patients who had experienced ovarian pathology and patients who had undergone previous ovarian surgery were excluded. All samples were frozen immediately in liquid nitrogen and stored at $-80^{\circ} \mathrm{C}$ until analysis.

Clinicopathological details of SOC patients were evaluated by reviewing medical charts and the original pathology reports. Staging and grading were determined in accordance with the criteria of the International Federation of Gynaecologists and Obstetricians (FIGO) and the World Health Organization (WHO). Follow-up data were obtained by reviewing the outpatient charts or via correspondence. Overall survival (OS) was defined as the time interval between the date of surgery and the date of death or end of follow-up (January 2013). This study was approved by the Research Ethics Committee of Fudan University, China. Informed consent was obtained from all of the patients.

Cell line and cell culture. Two paired human SOC cell lines: parental (SK-OV-3, HO8910) and highly metastatic sublines (SK-OV-3.ip1, HO8910-PM) (28-31) were gifts from the University of Texas M.D. Anderson Cancer Center (Houston, TX, USA). All cells were cultured in RPMI-1640 medium (Gibco BRL, Gaithersburg, MD, USA) containing 10\% fetal bovine serum (FBS; Gibco) with $100 \mathrm{U} / \mathrm{ml}$ penicillin and $100 \mathrm{mg} / \mathrm{ml}$ streptomycin and maintained in a humidified $5 \% \mathrm{CO}_{2}$ incubator at $37^{\circ} \mathrm{C}$.

Quantitative real-time PCR ( $q R T-P C R)$. Total RNA was isolated from cancerous/non-cancerous specimens or cell lines using TRIzol reagent (Invitrogen, Carlsbad, CA, USA). RNA was reverse transcribed into cDNAs using a Prime-Script ${ }^{\mathrm{TM}}$ one step RT-PCR kit (Takara, Dalian, China). QRT-PCR reactions were performed using an ABI7500 System (Applied Biosystems, Foster City, CA, USA) and SYBR Green PCR Master Mix (Takara). The primer sequences for ANRIL were 5'-TGTACTTAACCACTGGACTACCTGCC-3' (forward) and 5'-CATTCTGATTCAACAGCAGAGATCAAAG-3' (reverse). Glyceraldehyde 3-phosphate dehydrogenase (GAPDH) was applied as an internal control, the primers for which were 5'-GTCAACGGATTTGGTCTGTATT-3' (forward) and 5'-AGTCTTCTGGGTGGCAGTGAT-3' (reverse). Each assay was performed in triplicate, and the average was calculated. ANRIL expression levels were normalised to GAPDH.

Small interfering RNAs (siRNAs) and transfection. For the in vitro study, SK-OV-3.ip1 and HO8910-PM cells were transfected with either $50 \mathrm{nM}$ siRNAs targeting ANRIL or scrambled negative controls (GenePharma, Shanghai, China) using Lipofectamine 2000 transfection reagent (Invitrogen) according to the instructions provided by the manufacturer. The two siRNA sequences targeting 2 different sections of ANRIL were 5'-GCAAGAAACATTGCTGCTAGC-3' and 5'-GCCCAATTATGCTGTGGTAAC-3'. After 48 h of transfection, knockdown of ANRIL was confirmed via qRT-PCR.

Wound-healing assay. SK-OV-3.ip1 and HO8910-PM cells were transfected with either $50 \mathrm{nM}$ siRNAs targeting ANRIL or a scrambled negative control (si-NC). When cell confluence reached $\sim 80 \%$ at $24 \mathrm{~h}$ posttransfection, wounds were created in confluent cells using a $200-\mu 1$ pipette tip. Cells were then rinsed with medium to remove any free-floating cells and debris. Medium was added, and the culture plates were incubated at $37^{\circ} \mathrm{C}$. Different stages of wound healing were observed along the scrape line, and representative scrape lines were photographed. Duplicate wells for each condition were examined, and each experiment was repeated in triplicate.

Matrigel invasion assay. SK-OV-3.ip1 and HO8910-PM cells were transfected with $50 \mathrm{nM}$ siRNAs targeting ANRIL or a scrambled negative control (si-NC). At $24 \mathrm{~h}$ post-infection, infected cells were harvested and subjected to the following assays. Infected cells $\left(1 \times 10^{5}\right)$ were plated in the top chamber of Transwell assay inserts (Millipore, Billerica, MA, USA) with a Matrigel coated membrane containing pores with a diameter of $8 \mu \mathrm{m}$ in $200 \mathrm{ml}$ of serum-free RPMI-1640. The assays were conducted in triplicate. Inserts were then placed into the bottom chamber wells of a 24-well plate containing RPMI-1640 with $10 \%$ FBS as a chemo-attractant. After $48 \mathrm{~h}$ of incubation, the remaining cells were removed from the top layer of the insert by scrubbing with a sterile cotton swab. Invading cells from the bottom surface were stained with $0.1 \%$ crystal violet prior to being examined, counted, and photographed using digital microscopy. Cell numbers were calculated in five random fields for each chamber, and the average value was calculated.

Western blotting. The cells were lysed with RIPA buffer [50 mM Tris- $\mathrm{HCl}$ (pH 7.5), $150 \mathrm{mM} \mathrm{NaCl}, 1 \%$ Triton X-100, $0.5 \%$ Na-deoxycholate] containing protease inhibitors (Roche, Complete Mini). Lysate aliquots (20-30 $\mu \mathrm{g}$ ) were separated on $10 \%$ sodium dodecyl sulphate-polyacrylamide gel electrophoresis (SDS-PAGE) gels and transferred to a polyvinyl 

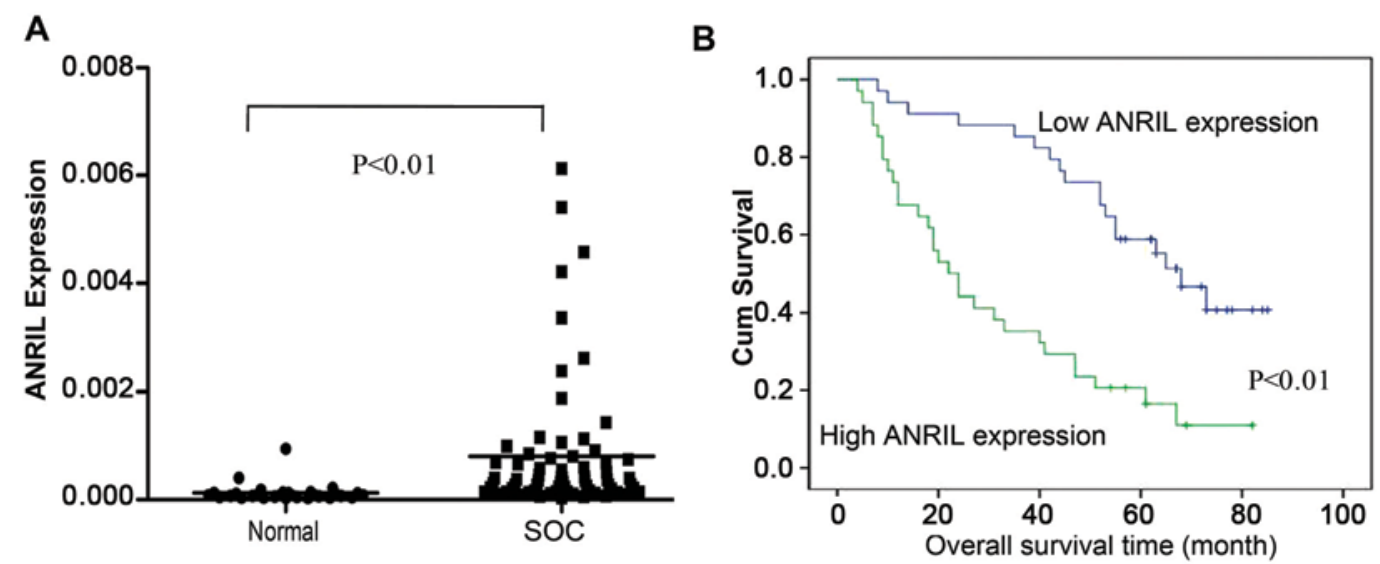

Figure 1. Relative ANRIL expression levels and their association with poor prognosis in serous ovarian cancer. (A) Relative ANRIL expression in serous ovarian cancer tissues and normal ovarian tissues. (B) Kaplan-Meier survival analysis of patients with high and low levels of ANRIL expression.

difluoride (PVDF) membrane. The membranes were incubated with the primary antibodies (Cell Signalling) rabbit antiMMP3, anti-MET and anti-GAPDH overnight at $4^{\circ} \mathrm{C}$. Primary antibody incubation was followed with HRP-conjugated secondary antibody incubation. The bound antibodies were detected with ECL kit (Pierce, PI32209).

Tumour metastasis real-time PCR array. Total RNA was extracted from SK-OV-3.ip1-ANRIL-siRNA1 cells and SK-OV-3.ip1-si-NC cells with an RNeasy mini kit (Qiagen) and further purified using an RNeasy MinElute ${ }^{\mathrm{TM}}$ Cleanup kit (Qiagen). An RT ${ }^{2}$ First Strand kit (Qiagen) was employed to produce a cDNA library for the total RNA extracted. Following the manufacturer's protocol, the cDNA was then processed to perform a Human Tumour Metastasis $\mathrm{RT}^{2}$ Profiler $^{\mathrm{TM}}$ PCR array (Qiagen, Mississauga, ON, Canada) containing 84 genes known to be related to tumour metastasis, five housekeeping genes were used for a genomic DNA control, and three positive controls to ensure high-quality data normalisation across samples. The results were analysed using SA Biosciences software. For relative quantification, $2^{-\Delta \Delta C t}$ was calculated and used as an indication of the relative expression level.

Statistical analysis. All of the statistical analyses were performed using SPSS for Windows v.16.0 (SPSS, Chicago, IL, USA). The continuous data were analysed using an independent $\mathrm{t}$-test between the two groups, whereas categorical data were analysed by the $\chi^{2}$ test or Fisher's exact test, as appropriate. OS curves were plotted according to the Kaplan-Meier method, and the log-rank test was applied for comparison. The variables were used in multivariate analysis on the basis of the Cox proportional hazards model. P-values $<0.05$ were considered statistically significant $(\mathrm{P}<0.05)$.

\section{Results}

ANRIL is overexpressed and correlates with poor prognosis in SOC. ANRIL expression levels in $68 \mathrm{SOC}$ and 30 noncancerous tissues were examined using qRT-PCR. The results showed that ANRIL levels in SOC tissues were significantly higher than those in non-cancerous tissues $(\mathrm{P}<0.01$; Fig. 1A).
Table I. Association of ANRIL expression with clinicopathological variables in 68 SOC patients.

\begin{tabular}{|c|c|c|c|}
\hline & $\begin{array}{c}\text { Low } \\
\text { ANRIL } \\
\text { expression } \\
(\mathrm{n}=34) \\
\end{array}$ & $\begin{array}{c}\text { High } \\
\text { ANRIL } \\
\text { expression } \\
(\mathrm{n}=34) \\
\end{array}$ & \\
\hline Variables & $\mathrm{n}(\%)$ & $\mathrm{n}(\%)$ & P-value \\
\hline \multicolumn{4}{|c|}{ Age (years) } \\
\hline$<50$ & $11(42.3)$ & $15(57.7)$ & 0.318 \\
\hline$\geq 50$ & $23(54.8)$ & $19(45.2)$ & \\
\hline \multicolumn{4}{|c|}{ FIGO stage } \\
\hline I-II & $15(78.9)$ & $4(21.1)$ & 0.006 \\
\hline III-IV & $19(38.8)$ & $30(61.2)$ & \\
\hline \multicolumn{4}{|c|}{ Histological grade } \\
\hline G1-G2 & $16(66.7)$ & $8(33.3)$ & 0.042 \\
\hline G3 & $18(40.9)$ & $26(59.1)$ & \\
\hline \multicolumn{4}{|c|}{$\begin{array}{l}\text { Residual tumour } \\
\text { diameter }(\mathrm{cm})\end{array}$} \\
\hline$<1$ & $26(56.5)$ & $20(43.5)$ & 0.12 \\
\hline$\geq 1$ & $8(36.4)$ & $14(63.6)$ & \\
\hline \multicolumn{4}{|c|}{$\begin{array}{l}\text { Lymph node } \\
\text { metastasis }\end{array}$} \\
\hline Absent & $21(75.0)$ & $7(25.0)$ & 0.001 \\
\hline Present & $13(32.5)$ & $27(67.5)$ & \\
\hline \multicolumn{4}{|c|}{ CA125 level (U/ml) } \\
\hline$<600$ & $15(48.4)$ & $16(51.6)$ & 0.808 \\
\hline$\geq 600$ & $19(51.4)$ & $18(48.6)$ & \\
\hline \multicolumn{4}{|l|}{ Ascites } \\
\hline$<100$ & $16(61.5)$ & $10(38.5)$ & 0.134 \\
\hline$\geq 100$ & $18(42.9)$ & $24(57.1)$ & \\
\hline
\end{tabular}

For the clinicopathological correlation analysis, the $68 \mathrm{SOC}$ patients were divided into two groups according to the 
Table II. Univariate and multivariate analysis of overall survival in 68 SOC patients.

\begin{tabular}{|c|c|c|c|c|c|c|c|c|}
\hline \multirow[b]{3}{*}{ Variables } & \multirow{2}{*}{\multicolumn{2}{|c|}{$\begin{array}{c}\text { Univariate analysis } \\
\begin{array}{c}\text { Overall survival } \\
\text { (months) }\end{array}\end{array}$}} & \multicolumn{6}{|c|}{ Multivariate analysis } \\
\hline & & & \multicolumn{6}{|c|}{ Overall survival } \\
\hline & Mean \pm SE & P-value & $\beta$ & SE & Wald & P-value & $\operatorname{Exp}(\beta)$ & $95 \%$ CI \\
\hline \multicolumn{9}{|c|}{ Age (years) } \\
\hline$<50$ & $42.67 \pm 4.83$ & 0.341 & - & - & - & - & - & - \\
\hline$\geq 50$ & $49.29 \pm 4.68$ & & - & - & - & - & - & - \\
\hline \multicolumn{9}{|c|}{ FIGO stage } \\
\hline I-II & $78.96 \pm 2.60$ & $<0.001$ & - & - & - & - & - & - \\
\hline III-IV & $35.00 \pm 3.44$ & & 1.489 & 0.674 & 4.877 & 0.027 & 4.431 & $1.182-16.605$ \\
\hline \multicolumn{9}{|c|}{ Histological grade } \\
\hline G1-G2 & $66.02 \pm 5.10$ & $<0.001$ & - & - & - & - & - & - \\
\hline G3 & $36.82 \pm 3.85$ & & 0.918 & 0.38 & 5.844 & 0.016 & 2.504 & $1.190-5.271$ \\
\hline \multicolumn{9}{|c|}{$\begin{array}{l}\text { Residual tumour } \\
\text { diameter }(\mathrm{cm})\end{array}$} \\
\hline$<1$ & $54.36 \pm 4.39$ & 0.001 & - & - & - & - & - & - \\
\hline$\geq 1$ & $33.24 \pm 4.88$ & & 0.307 & 0.313 & 0.962 & 0.327 & 1.359 & $0.736-2.508$ \\
\hline \multicolumn{9}{|c|}{ CA125 level (U/ml) } \\
\hline$<600$ & $53.61 \pm 4.92$ & 0.142 & - & - & - & - & - & - \\
\hline$\geq 600$ & $42.37 \pm 4.89$ & & - & - & - & - & - & - \\
\hline \multicolumn{9}{|c|}{ Lymph node metastasis } \\
\hline Absent & $71.97 \pm 3.53$ & $<0.001$ & - & - & - & - & - & - \\
\hline Present & $29.28 \pm 3.18$ & & 1.523 & 0.47 & 10.479 & 0.001 & 4.584 & $1.823-11.523$ \\
\hline \multicolumn{9}{|l|}{ Ascites } \\
\hline$<100$ & $51.55 \pm 5.50$ & 0.511 & - & - & - & - & - & - \\
\hline$\geq 100$ & $44.78 \pm 4.56$ & & - & - & - & - & - & - \\
\hline \multicolumn{9}{|c|}{ ANRIL expression } \\
\hline Low & $62.44 \pm 4.19$ & $<0.001$ & - & - & - & - & - & - \\
\hline High & $32.05 \pm 4.31$ & & 0.639 & 0.317 & 4.059 & 0.044 & 1.895 & $1.018-3.530$ \\
\hline
\end{tabular}

$\beta$, Regression coefficient; SE, standard error; CI, confidence interval.

median relative ANRIL expression value that was used as the cut-off (10): high ANRIL group ( $n=34)$ : ANRIL expression value $\geq$ the 50 th percentile (with an average $\Delta \mathrm{Ct}$ expression value of 10.046 compared to GAPDH); low ANRIL group $(n=34)$ : ANRIL expression value less than the 50th percentile (with an average $\Delta \mathrm{Ct}$ expression value of 12.584 compared to GAPDH). As shown in Table I, elevated ANRIL expression was correlated with advanced FIGO stage, high histological grade and lymph node metastasis, but not with age, residual tumour diameter, CA125 level or ascites.

The OS curves calculated using the Kaplan-Meier method according to ANRIL expression are shown in Fig. 1B. According to the univariate analysis, ANRIL expression was correlated with OS $(\mathrm{P}<0.001$, Table II). Using a multivariate Cox regression analysis, ANRIL expression, in addition to FIGO stage, histological grade and lymph node metastasis, was an independent predictor of $\mathrm{OS}(\mathrm{P}<0.01$, Table II).
These results suggest that ANRIL can be used as a powerful independent prognostic factor and that overexpression of ANRIL might have an important role in SOC progression.

ANRIL expression in SOC cell lines. Because overexpression of ANRIL was associated with lymph node metastasis and poor prognosis, we speculated that ANRIL might play a role in mediating SOC metastasis. To explore this possibility, we examined ANRIL levels in two paired SOC cell lines: parental (SK-OV-3, HO8910) and highly metastatic sublines (SK-OV-3. ip1, HO8910-PM). The results showed that SK-OV-3.ip1 and HO8910-PM expressed higher levels of ANRIL than their parental cell lines (Fig. 2), suggesting that ANRIL was associated with SOC metastasis.

ANRIL silencing attenuates migration and invasion of SOC cells. To further investigate the role of ANRIL in SOC 
A

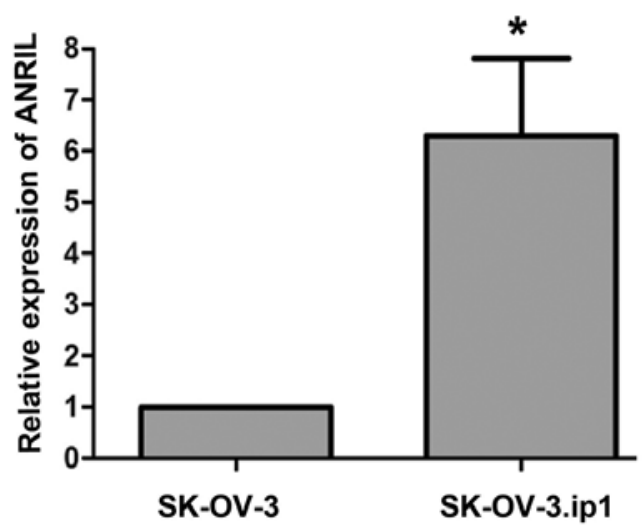

B

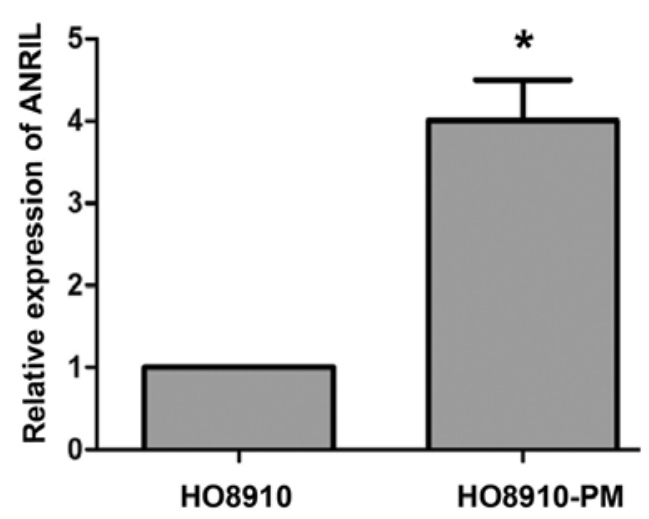

Figure 2. Relative ANRIL expression levels in serous ovarian cancer cell lines. (A) Relative ANRIL expression in parental SK-OV-3 and highly metastatic subline SK-OV-3.ip1 ( $\left.{ }^{*} \mathrm{P}<0.01\right)$. The data represent the mean \pm standard deviation (SD) of three independent experiments. The error bars denote the SD. (B) Relative ANRIL expression in parental HO8910 and highly metastatic subline HO8910-PM ( $\left.{ }^{*}<0.01\right)$. The data represent the mean \pm SD of three independent experiments. The error bars denote the SD.
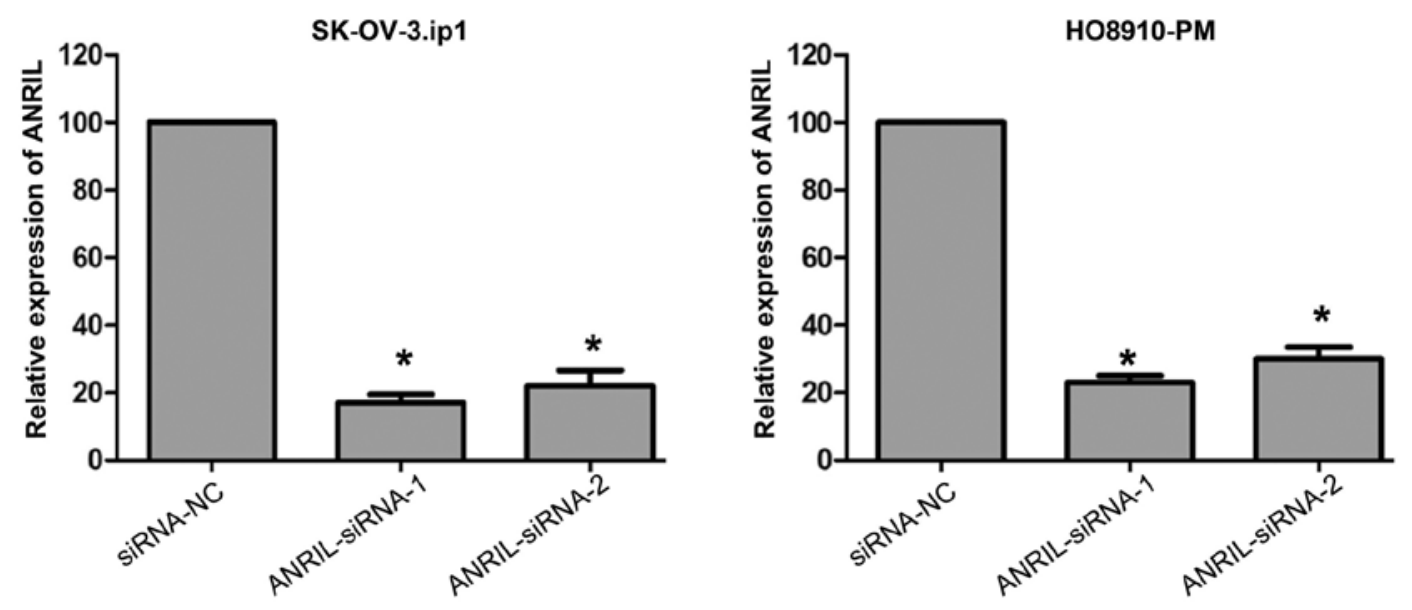

Figure 3. Relative ANRIL expression in SK-OV-3.ip1 and HO8910-PM cells transfected with si-NC or si-ANRIL. The data represent the mean \pm SD of three independent experiments. The error bars denote the SD. ${ }^{*} \mathrm{P}<0.01$.

metastasis, the effects of siRNA-mediated knockdown of ANRIL expression were first investigated in SK-OV-3.ipl and HO8910-PM cells. Forty-eight hours following treatment, both siRNAs efficiently knocked down ANRIL expression in these cells (Fig. 3).

We then assessed the effects of ANRIL on the migratory and invasive behaviour of SOC cells. Wound-healing assays showed that knockdown of ANRIL caused an apparent suppression of cell migration in both SK-OV-3.ip1 and HO8910-PM cells ( $\mathrm{P}<0.01$, Fig. 4A). Matrigel invasion assays also demonstrated that depletion of ANRIL markedly reduced the invasive ability of both SK-OV-3.ip1 and HO8910-PM cells $(\mathrm{P}<0.01$, Fig. 4B). We therefore concluded that ANRIL promotes SOC cell migration and invasion in vitro.

MET and MMP3 are the key downstream genes of ANRIL involved in SOC cell metastasis. To further study possible mechanisms through which ANRIL alters migration and invasion in SOC cells, tumour metastasis-related gene expression profiles of SK-OV-3.ip1-ANRIL-siRNA1 cells were first compared with those of SK-OV-3.ip1-si-NC cells using real-time PCR array analysis. The results showed that six genes were markedly dysregulated ( $>2$-fold) after ANRIL silencing in SK-OV-3.ip1 cells, specifically four downregulated (MMP3, MTA1, FN1 and MET) and two upregulated (CDH1 and TIMP2) genes (Table III).

These downstream genes were further validated by qRT-PCR and western blotting assays in both SK-OV-3. ip1 and HO8910-PM cells. Consistent with the array results, decreased MET and MMP3 mRNA and protein levels were detected by qRT-PCR and western blotting in both SK-OV-3. ip1 and HO8910-PM cells after ANRIL silencing with both siRNAs (Fig. 5).

Taken together, these data indicate that ANRIL regulates SOC cell migration and invasion, at least in part, through the regulation of MET and MMP3. 
A

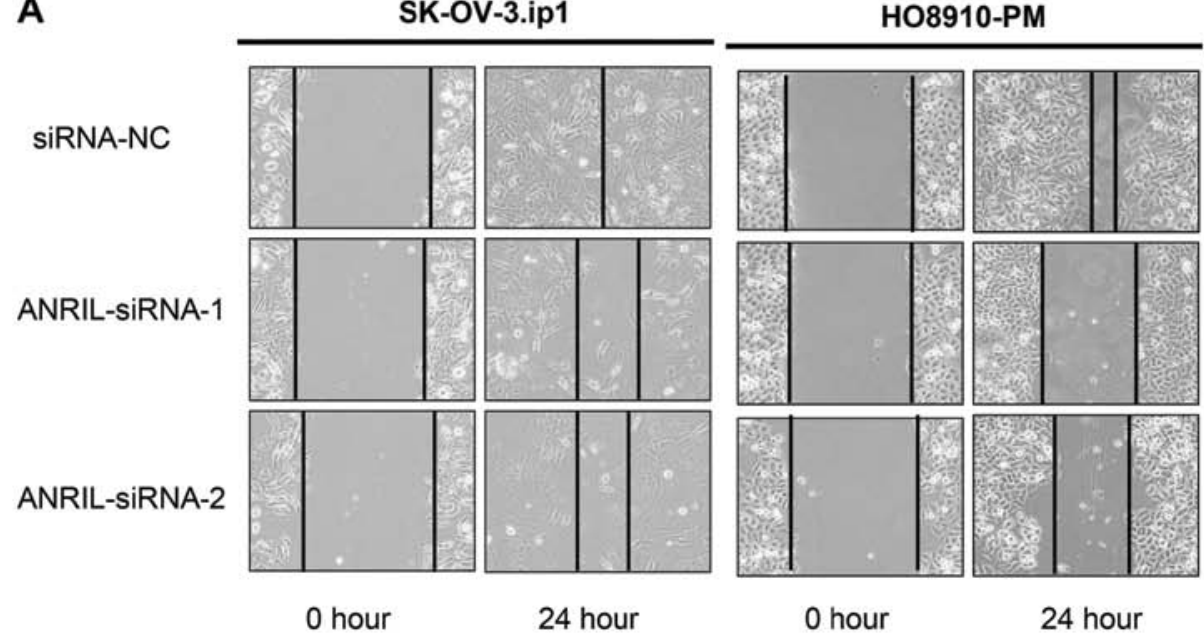

B

SK-OV-3.ip1

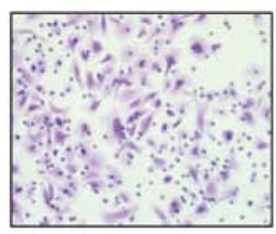

SiRNA-NC

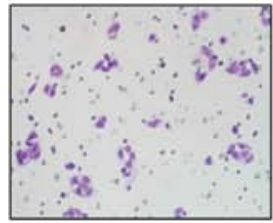

SiRNA-NC

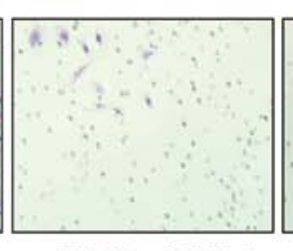

ANRIL-SiRNA-1

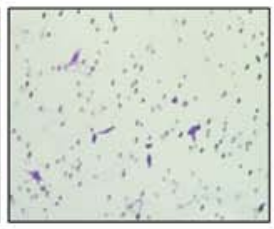

ANRIL-siRNA-1
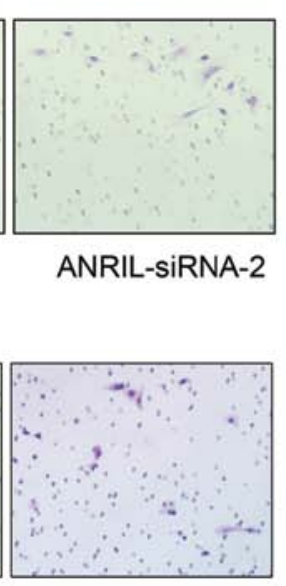

ANRIL-SIRNA-2
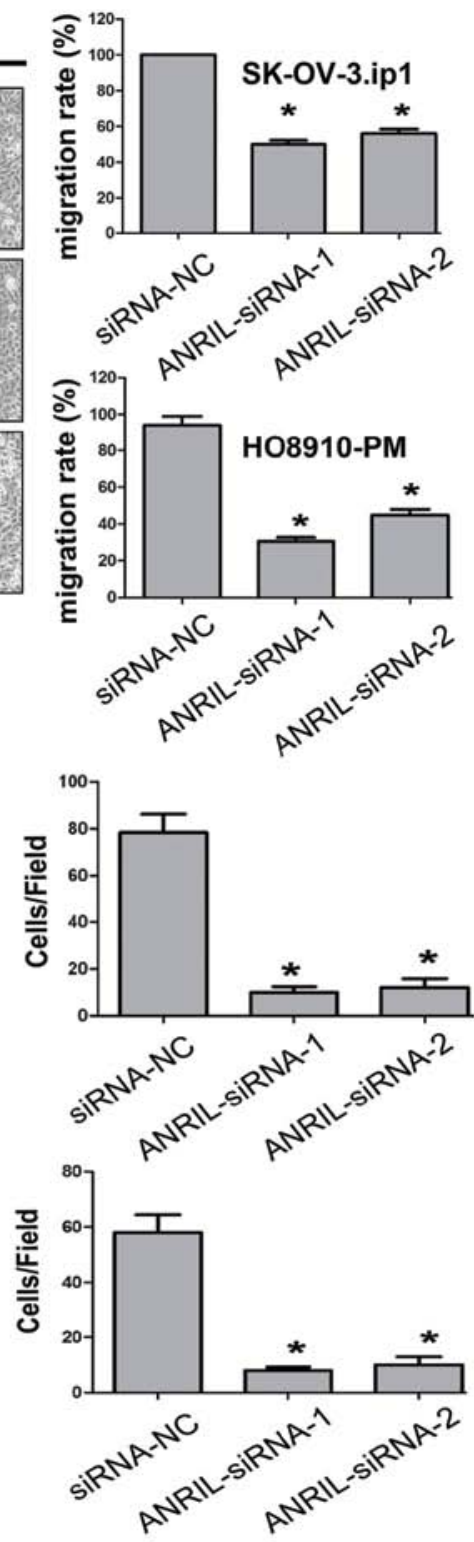

Figure 4. The knockdown of ANRIL inhibits migration and invasion in SK-OV-3.ip1 and HO8910-PM cells. (A) Wound-healing assay of SK-OV-3.ip1 and HO8910-PM cells transfected with si-NC or si-ANRIL ( $\mathrm{P}<0.01$ ). The data represent the mean $\pm \mathrm{SD}$ of three independent experiments. The error bars denote the SD. (B) Transwell assay of SK-OV-3.ip1 and HO8910-PM cells transfected with si-NC or si-ANRIL ("P<0.01). The data represent the mean \pm SD of three independent experiments. The error bars denote the SD.

Table III. Genes dysregulated >2-fold after ANRIL silencing in SK-OV-3.ip1 cells identified by array.

\begin{tabular}{llllr}
\hline Gene name & GeneBank ID & \multicolumn{1}{c}{ Description } & \multicolumn{1}{c}{ Function } & Fold change \\
\hline CDH1 & NM_004360 & Cadherin 1, type 1, E-cadherin & Inhibits tumour metastasis & 2.38 \\
FN1 & NM_002026 & Fibronectin 1 & Participates in cell adhesion & -2.25 \\
MET & NM_000245 & Met proto-oncogene & Protooncogene, promotes cell proliferation & -3.21 \\
MMP3 & NM_002422 & Matrix metallopeptidase 3 & Promotes metastasis & -3.83 \\
MTA1 & NM_004689 & Metastasis associated 1 & Promotes metastasis & -2.36 \\
TIMP2 & NM_003255 & TIMP metallopeptidase inhibitor 2 & Inhibits metastasis & 2.19 \\
\hline
\end{tabular}

\section{Discussion}

Mounting evidence indicates that eukaryotic transcriptomes and genomes are not the simple substrates of protein-coding gene transcription that they were once thought to be, but rather exhibit extensive non-coding RNA (ncRNA) expression (6). Recent studies have highlighted the role of long ncRNAs (lncRNAs) in carcinogenesis and have suggested that this class 
A

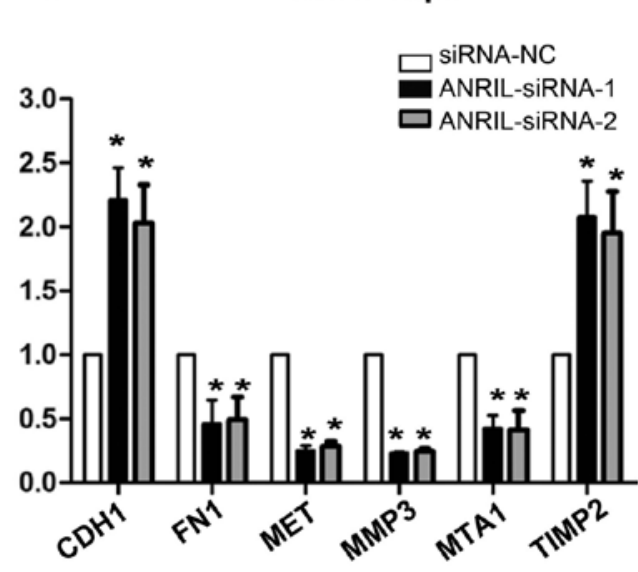

B
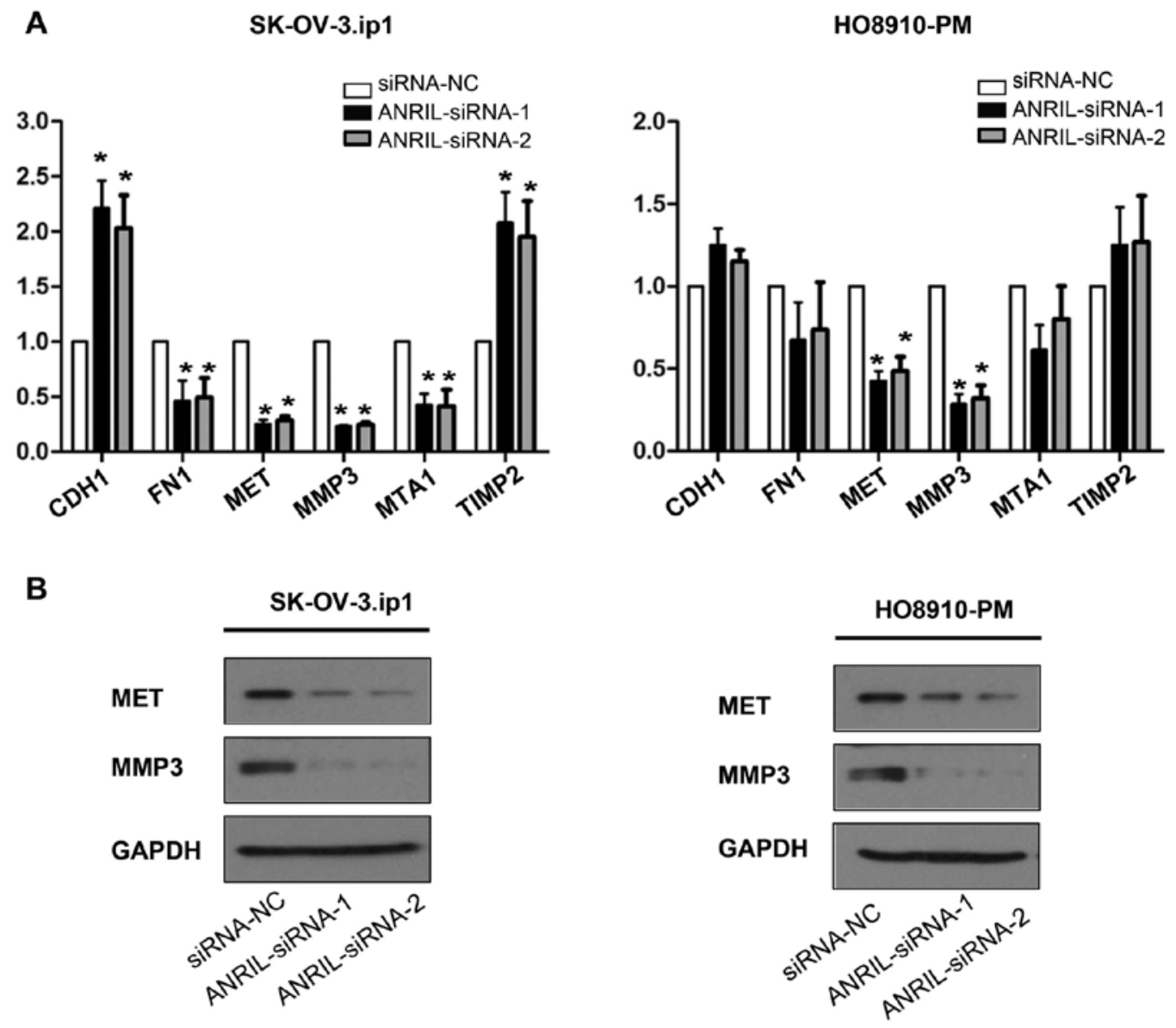

Figure 5. Decreased expression of MET and MMP3 following ANRIL knockdown. (A) QRT-PCR analysis of relative MET and MMP3 expression in SK-OV-3.ip1 and HO8910-PM cells transfected with si-NC or si-ANRIL ("P<0.01). The data represent the mean \pm SD of three independent experiments. The error bars denote the SD. (B) WB examination of MMP3 and MET expression in SK-OV-3.ip1 and HO8910-PM cells transfected with si-NC or si-ANRIL.

of genes might be used as biomarkers in cancer. For example, HOTAIR has been demonstrated to be upregulated in primary breast tumours and metastases, and elevated HOTAIR expression is an indispensable predictor of eventual metastasis and death (8). MALAT-1 has been found to promote cell motility and predict poorer clinical outcome in lung cancer (9). HULC has been implicated in the regulation of hepatoma cancer cell proliferation, and higher HULC expression can be used as a non-invasive promising novel biomarker for diagnosis and/or prognosis in hepatocellular carcinoma $(32,33)$. These studies emphasise the roles and clinical significance of IncRNAs in cancer biology.

ANRIL, transcribed as a $3.8-\mathrm{kb}$ lncRNA in the opposite direction from the INK4b/ARF/INK4a gene cluster, was first identified following genetic analysis of familial melanoma patients with neural tumours (19). Recently, some genomewide association studies have identified ANRIL as a risk locus for several other cancers, including breast cancer, pancreatic carcinoma, nasopharyngeal carcinoma, basal cell carcinoma, glioma and leukemia (22-27). Inspired by these lines of evidence, we investigated ANRIL expression in SOC and analysed its clinical significance in the present study. Our data revealed that ANRIL expression levels in SOC tissues were clearly higher than those in non-cancerous tissues, strongly suggesting the possibility that ANRIL can be used as a potential biomarker to detect SOC. Furthermore, elevated ANRIL expression was associated with advanced FIGO stage, high histological grade and lymph node metastasis, indicating that overexpression of ANRIL may facilitate a more malignant ovarian cancer phenotype as well as metastasis. Importantly, the univariate and multivariate survival analyses showed that overexpression of ANRIL was an independent factor for predicting OS in SOC patients, demonstrating that ANRIL may act as a crucial prognostic biomarker for SOC patients. Thus, the examination of ANRIL expression could be used as an additional tool in identifying those SOC patients at increased risk for tumour metastasis and/or a poorer prognosis.

Previous studies have revealed that ANRIL contributes to various cellular events in many cancers, such as facilitated cell proliferation and senescence $(20,21)$, suggesting a pro-cancerogenic role of the transcript. Encouraged by these earlier studies and our findings that overexpression of ANRIL was associated with lymph node metastasis and poor prognosis, it is therefore a logically hypothesis that ANRIL may be involved in SOC metastasis. Consistent with this hypothesis, our data demonstrated that ANRIL expression levels in highly metastatic SOC cell sublines (SK-OV-3.ip1 and HO8910-PM) were significantly higher than those in parental cells (SK-OV-3 and HO8910), indicating the metastatic potential of ANRIL. Subsequent wound-healing and Matrigel invasion assays showed that siRNA-mediated knockdown of ANRIL attenuated the ability of either cell migration or invasion in both 
SK-OV-3.ip1 and HO8910-PM cells. These results collectively suggest that ANRIL is an important factor for cell migration and invasion of SOC.

To date, the regulatory molecular events associated with ANRIL are not clear. Several previous reports have established that ANRIL has a regulatory effect on its neighbours CDKN2A/B $(20,21,34)$; however, there is also evidence that ANRIL acts on certain genes that do not appear to be downstream to $\mathrm{CDKN} 2 \mathrm{~A} / \mathrm{B}(35,36)$, reflecting a very complex regulatory panorama for this IncRNA. To investigate the downstream molecular events involving ANRIL and SOC invasiveness and/or metastasis in the current study, we compared SK-OV-3. ip1-ANRIL-siRNA1 cells and SK-OV-3.ip1-si-NC cells using a human tumour metastasis real-time PCR array, containing 84 well-known cell invasion/metastasis-related genes. Notably, the mRNAs of six genes were differentially expressed ( $>2$-fold; i.e., MMP3, MTA1, FN1 and MET were downregulared, and CDH1 and TIMP2 were upregulated). Subsequently, downregulation of MET and MMP3 protein was confirmed by western blotting in both SK-OV-3.ip1 and HO8910-PM cells. Taken together, these results suggest that ANRIL might regulate SOC cell migration/invasion by regulating MET and MMP3. Future efforts will be devoted to exploring the underlying molecular mechanism through which ANRIL regulates MET and MMP3.

In conclusion, ANRIL is overexpressed in SOC, and its overexpression correlates with an aggressive/poor prognostic phenotype of the tumour. Furthermore, functional studies suggest a critical role of ANRIL in the control of SOC cell migration/invasion at least in part through regulation of MET and MMP3. These data highlight the significance of ANRIL in SOC progression, suggesting that ANRIL may be a crucial predictor for SOC metastasis/poor prognosis and a potential therapeutic target.

\section{Acknowledgements}

This study was supported by funding from the National Natural Science Foundation of China (81370689; to K.-Q.H.) and from Shanghai Science and Technology Development Funds for the Talents (15YF1401400; to J.-J.Q.).

\section{References}

1. Siegel R, Naishadham D and Jemal A: Cancer statistics, 2012. CA Cancer J Clin 62: 10-29, 2012.

2. Bowtell DD: The genesis and evolution of high-grade serous ovarian cancer. Nat Rev Cancer 10: 803-808, 2010.

3. Feigenberg T, Clarke B, Virtanen C, Plotkin A, Letarte M, Rosen B, Bernardini MQ, Kollara A, Brown TJ and Murphy KJ: Molecular profiling and clinical outcome of high-grade serous ovarian cancer presenting with low- versus high-volume ascites. Biomed Res Int 2014: 367103, 2014.

4. Lengyel E: Ovarian cancer development and metastasis. Am J Pathol 177: 1053-1064, 2010.

5. Rustin G, van der Burg M, Griffin C, Qian W and Swart AM: Early versus delayed treatment of relapsed ovarian cancer. Lancet 377: 380-381, 2011.

6. Wilusz JE, Sunwoo H and Spector DL: Long noncoding RNAs: Functional surprises from the RNA world. Genes Dev 23: 1494-1504, 2009.

7. Nagano $\mathrm{T}$ and Fraser P: No-nonsense functions for long noncoding RNAs. Cell 145: 178-181, 2011.

8. Gupta RA, Shah N, Wang KC, Kim J, Horlings HM, Wong DJ, Tsai MC, Hung T, Argani P, Rinn JL, et al: Long non-coding RNA HOTAIR reprograms chromatin state to promote cancer metastasis. Nature 464: 1071-1076, 2010.
9. Gutschner T, Hämmerle M, Eissmann M, Hsu J, Kim Y, Hung G, Revenko A, Arun G, Stentrup M, Gross M, et al: The noncoding RNA MALAT1 is a critical regulator of the metastasis phenotype of lung cancer cells. Cancer Res 73: 1180-1189, 2013.

10. Yuan SX, Yang F, Yang Y, Tao QF, Zhang J, Huang G, Yang Y, Wang RY, Yang S, Huo XS, et al: Long noncoding RNA associated with microvascular invasion in hepatocellular carcinoma promotes angiogenesis and serves as a predictor for hepatocellular carcinoma patients' poor recurrence-free survival after hepatectomy. Hepatology 56: 2231-2241, 2012.

11. de Kok JB, Verhaegh GW, Roelofs RW, Hessels D, Kiemeney LA, Aalders TW, Swinkels DW and Schalken JA: DD3(PCA3), a very sensitive and specific marker to detect prostate tumors. Cancer Res 62: 2695-2698, 2002.

12. Sun M, Xia R, Jin F, Xu T, Liu Z, De W and Liu X: Downregulated long noncoding RNA MEG3 is associated with poor prognosis and promotes cell proliferation in gastric cancer. Tumour Biol 35: 1065-1073, 2014.

13. Quagliata L, Matter MS, Piscuoglio S, Arabi L, Ruiz C, Procino A, Kovac M, Moretti F, Makowska Z, Boldanova T, et al: Long noncoding RNA HOTTIP/HOXA13 expression is associated with disease progression and predicts outcome in hepatocellular carcinoma patients. Hepatology 59: 911-923, 2014.

14. Ge X, Chen Y, Liao X, Liu D, Li F, Ruan H and Jia W: Overexpression of long noncoding RNA PCAT-1 is a novel biomarker of poor prognosis in patients with colorectal cancer. Med Oncol 30: 588, 2013.

15. Wang XS, Zhang Z, Wang HC, Cai JL, Xu QW, Li MQ, Chen YC, Qian XP, Lu TJ, Yu LZ, et al: Rapid identification of UCA1 as a very sensitive and specific unique marker for human bladder carcinoma. Clin Cancer Res 12: 4851-4858, 2006.

16. Tano $\mathrm{K}$ and Akimitsu N: Long non-coding RNAs in cancer progression. Front Genet 3: 219, 2012.

17. Yu W, Gius D, Onyango P, Muldoon-Jacobs K, Karp J, Feinberg AP and Cui H: Epigenetic silencing of tumour suppressor gene p15 by its antisense RNA. Nature 451: 202-206, 2008.

18. El Messaoudi-Aubert S, Nicholls J, Maertens GN, Brookes S, Bernstein E and Peters G: Role for the MOV10 RNA helicase in polycomb-mediated repression of the INK4a tumor suppressor. Nat Struct Mol Biol 17: 862-868, 2010.

19. Pasmant E, Laurendeau I, Héron D, Vidaud M, Vidaud D and Bièche I: Characterization of a germ-line deletion, including the entire INK4/ARF locus, in a melanoma-neural system tumor family: Identification of ANRIL, an antisense noncoding RNA whose expression coclusters with ARF. Cancer Res 67: 3963-3969, 2007.

20. Kotake Y, Nakagawa T, Kitagawa K, Suzuki S, Liu N, Kitagawa M and Xiong Y: Long non-coding RNA ANRIL is required for the PRC2 recruitment to and silencing of p15(INK4B) tumor suppressor gene. Oncogene 30: 1956-1962, 2011.

21. Yap KL, Li S, Muñoz-Cabello AM, Raguz S, Zeng L, Mujtaba S, Gil J, Walsh MJ and Zhou MM: Molecular interplay of the noncoding RNA ANRIL and methylated histone $\mathrm{H} 3$ lysine 27 by polycomb CBX7 in transcriptional silencing of INK4a. Mol Cell 38: 662-674, 2010.

22. Turnbull C, Ahmed S, Morrison J, Pernet D, Renwick A, Maranian M, Seal S, Ghoussaini M, Hines S, Healey CS, et al: Breast Cancer Susceptibility Collaboration (UK): Genome-wide association study identifies five new breast cancer susceptibility loci. Nat Genet 42: 504-507, 2010.

23. Chen J, Li D, Wei C, Sen S, Killary AM, Amos CI, Evans DB, Abbruzzese JL and Frazier ML: Aurora-A and p16 polymorphisms contribute to an earlier age at diagnosis of pancreatic cancer in Caucasians. Clin Cancer Res 13: 3100-3104, 2007.

24. Bei JX, Li Y, Jia WH, Feng BJ, Zhou G, Chen LZ, Feng QS, Low HQ, Zhang H, He F, et al: A genome-wide association study of nasopharyngeal carcinoma identifies three new susceptibility loci. Nat Genet 42: 599-603, 2010.

25. Stacey SN, Sulem P, Masson G, Gudjonsson SA, Thorleifsson G, Jakobsdottir M, Sigurdsson A, Gudbjartsson DF, Sigurgeirsson B, Benediktsdottir KR, et al: New common variants affecting susceptibility to basal cell carcinoma. Nat Genet 41: 909-914, 2009.

26. Rajaraman P, Melin BS, Wang Z, McKean-Cowdin R, Michaud DS, Wang SS, Bondy M, Houlston R, Jenkins RB, Wrensch M, et al: Genome-wide association study of glioma and meta-analysis. Hum Genet 131: 1877-1888, 2012.

27. Sherborne AL, Hosking FJ, Prasad RB, Kumar R, Koehler R, Vijayakrishnan J, Papaemmanuil E, Bartram CR, Stanulla M, Schrappe M, et al: Variation in CDKN2A at 9p21.3 influences childhood acute lymphoblastic leukemia risk. Nat Genet 42 : 492-494, 2010. 
28. Yu D, Wolf JK, Scanlon M, Price JE and Hung MC: Enhanced c-erbB-2/neu expression in human ovarian cancer cells correlates with more severe malignancy that can be suppressed by E1A. Cancer Res 53: 891-898, 1993.

29. Bai F, Feng J, Cheng Y, Shi J, Yang R and Cui H: Analysis of gene expression patterns of ovarian cancer cell lines with different metastatic potentials. Int J Gynecol Cancer 16: 202-209, 2006.

30. Wang Y, Dong L, Cui H, Shen DH, Wang Y, Chang XH, Fu TY, Ye X and Yao YY: Up-regulation of mitochondrial antioxidation signals in ovarian cancer cells with aggressive biologic behavior. J Zhejiang Univ Sci B 12: 346-356, 2011.

31. Shenhua X, Lijuan Q, Hanzhou N, Xinghao N, Chihong Z, Gu Z, Weifang D and Yongliang G: Establishment of a highly metastatic human ovarian cancer cell line (HO-8910PM) and its characterization. J Exp Clin Cancer Res 18: 233-239, 1999.

32. Panzitt K, Tschernatsch MM, Guelly C, Moustafa T, Stradner M, Strohmaier HM, Buck CR, Denk H, Schroeder R, Trauner M, et al: Characterization of HULC, a novel gene with striking up-regulation in hepatocellular carcinoma, as noncoding RNA. Gastroenterology 132: 330-342, 2007.
33. Du Y, Kong G, You X, Zhang S, Zhang T, Gao Y, Ye L and Zhang X: Elevation of highly up-regulated in liver cancer (HULC) by hepatitis $\mathrm{B}$ virus $\mathrm{X}$ protein promotes hepatoma cell proliferation via down-regulating p18. J Biol Chem 287: 26302-26311, 2012.

34. Congrains A, Kamide K, Oguro R, Yasuda O, Miyata K, Yamamoto E, Kawai T, Kusunoki H, Yamamoto H, Takeya Y, et al: Genetic variants at the $9 \mathrm{p} 21$ locus contribute to atherosclerosis through modulation of ANRIL and CDKN2A/B. Atherosclerosis 220: 449-455, 2012.

35. Sato K, Nakagawa H, Tajima A, Yoshida K and Inoue I: ANRIL is implicated in the regulation of nucleus and potential transcriptional target of E2F1. Oncol Rep 24: 701-707, 2010

36. Congrains A, Kamide K, Katsuya T, Yasuda O, Oguro R, Yamamoto K, Ohishi M and Rakugi H: CVD-associated noncoding RNA, ANRIL, modulates expression of atherogenic pathways in VSMC. Biochem Biophys Res Commun 419: 612-616, 2012. 